\title{
The collection of five interesting cases of adrenal tumors from one medical center
}

\author{
Anna Babinska ${ }^{1 *}$, Rafał Peksa², Renata Swiątkowska-Stodulska ${ }^{1}$ and Krzysztof Sworczak
}

\begin{abstract}
Introduction: Adrenal tumors are detected incidentally in 4 to $8 \%$ of patients in imaging studies. Adenomas, pheochromocytomas and adrenocortical carcinomas represent the most common tumors of the adrenal glands. Rarely are final histopathological reports are surprising.

Aim: The aim of our study is a retrospective analysis of selected clinical characteristics and hormonal studies in five cases of rare adrenal tumors.

Materials and methods: We present five interesting cases of adrenal tumors: two medullary hyperplasia, one adenomatoid tumor, one hydatid cyst and a primary angiosarcoma of the adrenal gland. The final diagnosis was established by means of microscopic examination of the specimens.

Conclusions: The number of adrenal tumors was increased due to widespread use of imaging procedures. In patients without any known extra-adrenal malignancy most lesions are benign, non-hyper functioning adenomas. Adrenal tumors should be evaluated biochemically and radiologically.
\end{abstract}

Keywords: Medullary hyperplasia, Hydatid adrenal disease, Primary adrenal angiosarcoma, Adenomatoid tumor

\section{Background}

Adrenal tumors are detected incidentally in approximately 4 to $8 \%$ of patients in imaging studies [1]. Adenomas, pheochromocytomas and adrenocortical carcinomas represent the most common tumors of the adrenal glands. Most of them are benign tumors but careful evaluation is required to rule out carcinoma and functional adenoma $[1,2]$. We present five very rare, interesting cases of adrenal tumors selected from the material of $1,248 \mathrm{pa}-$ tients from the Department of Endocrinology and Internal Diseases, Medical University of Gdansk, Poland.

\section{Case presentation}

Cases one and two: medullary hyperplasia - AMH

(Adrenal medullary hyperplasia)

Two patients were admitted to our hospital in order to examine the cause of muscle weakness headaches, perspiration, palpitation and facial redness. A 46-year-old male presented with hypertension of 15-months duration (case

\footnotetext{
* Correspondence: a.mail@wp.pl

${ }^{1}$ Department of Endocrinology and Internal Medicine, Medical University of Gdansk, Gdansk, Dębinki St 80-288, Poland

Full list of author information is available at the end of the article
}

one). The patient's family had no history of hypertension, cardiac arrhythmias or thyroid disorders.

A 34-year-old female was referred for the evaluation of palpitation and facial redness of one-year's duration (case two). The patient's parents and sister had no history of hypertension or other endocrine disorders.

On admission, there were no cushingoid signs. Paroxysmal hypertension had occurred, and was poorly controlled by antihypertensive drugs in both cases. Levels of urinary catecholamines were increased during the paroxysmal hypertension (see Table 1). Thyroid scans revealed normal-sized glands and their basic serum calcitonin level was normal. Computer tomography (CT) scans revealed left adrenal masses measuring: $10 \mathrm{~mm}$ (patient one - Figure 1) and $30 \mathrm{~mm}$ (patient two). Both patients underwent preoperative medical management to block effects of catecholamines released during surgery. The patients underwent laparoscopic total adrenalectomy, with no postoperative complications. Surgery resulted in the normalization of catecholamine hypersecretion and clinical improvement in both patients (Table 1). A light microscopy revealed diffuse enlargement of the adrenal medulla from the head to tail in both cases. The adrenal 
Table 1 Hormonal characteristic of rare adrenal tumors

\begin{tabular}{|c|c|c|c|c|c|c|c|}
\hline $\begin{array}{l}\text { Patient } \\
\text { sex/age }\end{array}$ & Morphology & $\begin{array}{l}\text { DHEAS } \\
\text { serum }\end{array}$ & $\begin{array}{l}\text { Cortisol } \\
\text { urinary }\end{array}$ & $\begin{array}{l}\text { Cortisol serum } \\
\text { 8:00 am/8:00 pm }\end{array}$ & $\begin{array}{l}\text { Normetanephtines/ } \\
\text { metanephrines/VMA urinary }\end{array}$ & Observation time & Outcome \\
\hline$\overline{P 1}$ & Normal & 80.1 & 356 & $290 / 62$ & $700 / 550 /-$ & 3 years & NED \\
\hline \multirow[t]{2}{*}{$M / 46$} & & & & & & Normetanephrines 249 & \\
\hline & & & & & & Metanephrines 49.1 & \\
\hline P2 & Normal & 135 & 215 & $401.4 / 68.9$ & 690/442/- & 7 years & NED \\
\hline \multirow[t]{2}{*}{$F / 34$} & & & & & & Normetanephrines 387 & \\
\hline & & & & & & Metanephrines 189 & \\
\hline P3 & Eosinophilia 2,500/1 mm & 33 & 115 & $294 / 54$ & $529 / 229 /-$ & 11 years & NED \\
\hline$F / 47$ & & & & & & Eosinophilia 350/1 mm $\mathrm{mm}^{3}$ & \\
\hline P4 & Anemia & 18.15 & 400 & $502.4 / 68.9$ & $-/-/ 7.35$ & 2 years & Died \\
\hline$F / 64$ & $\begin{array}{l}\text { Hb 10.6; Hct 36.3; Mcv 85.4; } \\
\text { PLT 309; WBC 9.38 }\end{array}$ & & & & & & \\
\hline P5 & Normal & 425 & 120 & $748 / 132$ & $-/-15.2$ & 17 years & NED \\
\hline $\mathrm{F} / 40$ & & & & & & & \\
\hline
\end{tabular}

\section{Normal ranges:}

serum DHEAS (dehydroepiandrosterone sulphate): 34 to $430 \mathrm{ug} / \mathrm{dl}$;

24-hour cortisol urinary excretion: 12 to $486 \mathrm{nmol} / 24$ hours;

serum cortisol 8:00 am: 101 to $536 \mathrm{nmol} / \mathrm{dl}$;

serum cortisol 8:00 pm: 47 to $458 \mathrm{nmol} / \mathrm{dl}$;

$1 \mathrm{mg}$ Dexamethasone suppression test: $<50 \mathrm{nmol} / \mathrm{l}$;

24-hour normetanephrines urinary excretion: $<600 \mathrm{ug} / 24$ hours;

24-hour metanephrines excretion: $<350$ ug/24 hours;

24-hour vanilinmandelic acid (VMA): 4 to $8 \mathrm{mg} / 24$ hours;

NED: no evidence of disease.

cortex was normal in both cases. The combined corticomedullary ratio varied between 2:1 (patient one) and 4:1 (patient two), compared with a ratio of 10:1 in a normal gland (Figures 2, 3 and 4). The histopathological examination of the specimens showed diffuse adrenal medullary hyperplasia (AMH).

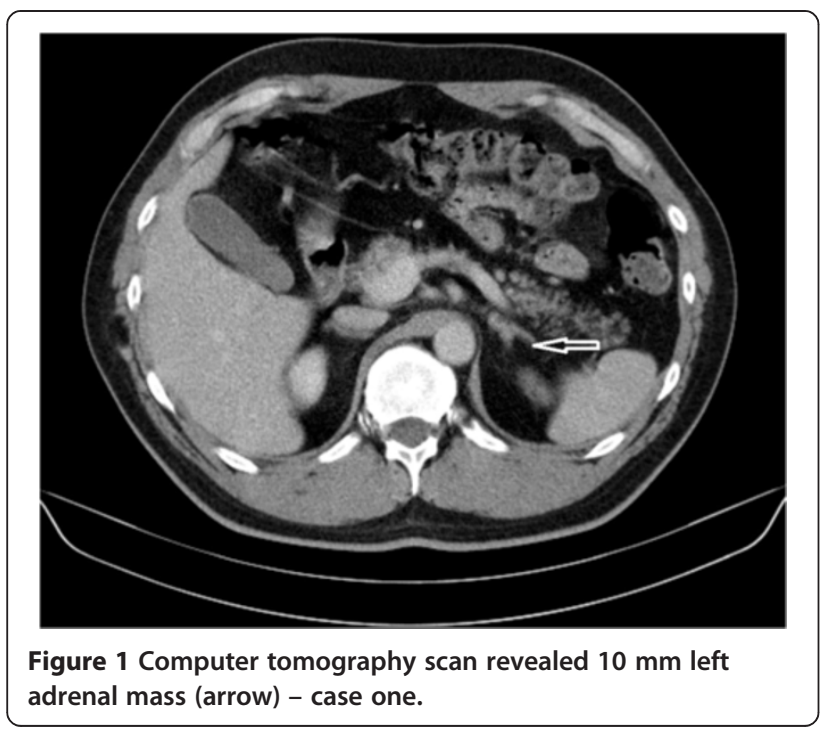

Case three: hydatid disease in the adrenal gland

We present the case of a woman with hydatid disease in her adrenal gland which was found incidentally in an ultrasonography (USG). A 47-year-old woman with two year history of arterial hypertension was referred to our department in 2003. A general examination revealed high blood pressure (180/100 mmHg). No other physical signs suggestive of hypercortisolism were noted. A blood analyses showed hypereosinophilia (see Table 1). A computed tomography (CT) scan of the abdomen demonstrated a sharply marginated, $55 \times 58 \times 68 \mathrm{~mm}$ right cystic mass with internal septa in the right adrenal gland. She underwent a laparoscopic adrenalectomy. In the surgical exploration, a solid cystic mass was defined, compressed against the right kidney's upper pole. The entire mass, together with normal adrenal tissue, was removed. According to a histopathological examination, hydatid disease in adrenal gland was suspected (Figure 5). Eosinophilia was normalized after surgery (see Table 1). Our patient has continued to be followed up on for 11 years without recurrence of hydatid disease.

\section{Case four: primary adrenal angiosarcoma}

We present the case of a 64-year-old woman with a malignant-looking right adrenal tumor, $87 \mathrm{~mm}$ in diameter. She was referred to our department in 2001. She 


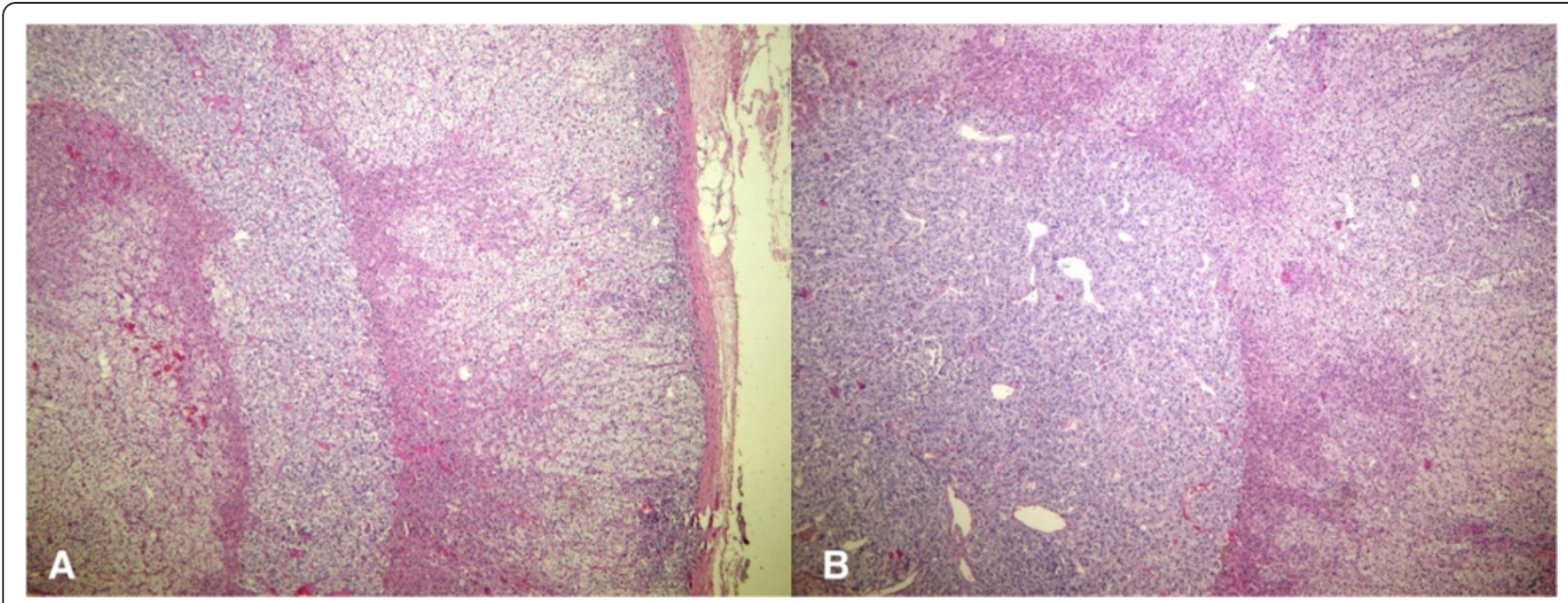

Figure 2 Diffuse and nodular adrenal medullary hyperplasia. There is vague nodularity in the medullary compartment (A) $(H \& E$, 40X magnification) - case one. There is also diffuse and nodular adrenal medullary hyperplasia and a visible diffuse pattern of hyperplasia (B) ( $H$ \& E, 40× magnification) - case two.

reported a $15 \mathrm{~kg}$ weight loss over the previous months and abdominal pain. Her medical history was hypertension and cholelithiasis for over 10 years previously. No other physical signs suggestive of hypercortisolism or pheochromocytoma were noted. A blood analyses showed anemia (see Table 1). As a part of the diagnostic procedures, her clinical examination was followed by an abdominal USG and CT scans. CT scans of the chest and abdomen showed a heterogenous mass of the right adrenal gland, $80 \times 78 \times 87 \mathrm{~mm}$ in diameter, without evidence of local tissue invasion or metastatic spread. Because of suspicion of malignancy, an open adrenalectomy was performed. After mobilization of the splenic flexure, a large mass was identified rising from the right adrenal gland. No obvious lymphadenopathy was seen. The mass was distinct and separate from the surrounding tissues.
The entire right adrenal gland containing the tumor was excised. A histopathological examination showed a primary adrenal angiosarcoma (PAA) (Figure 6). Upon immunohistochemical analysis, vascular antigens including CD (cluster of differentiation) 31, CD34 and vimentin, were expressed (Figure 7). Six months after the surgery, a whole body CT scan revealed no other primary tumor site, nor metastases. She died two years later of rapid recurrence of the disease, which metastasized to the bilateral lungs and liver. The chemotherapy plan was doxorubicin and ifosfamide but she refused the treatment.

\section{Case five: adenomatoid tumor of the adrenal gland}

Here we present the case of a 40-year-old woman with an adenomatoid tumor (AT) of the adrenal gland, clinically suspected to be a malignant tumor. The right

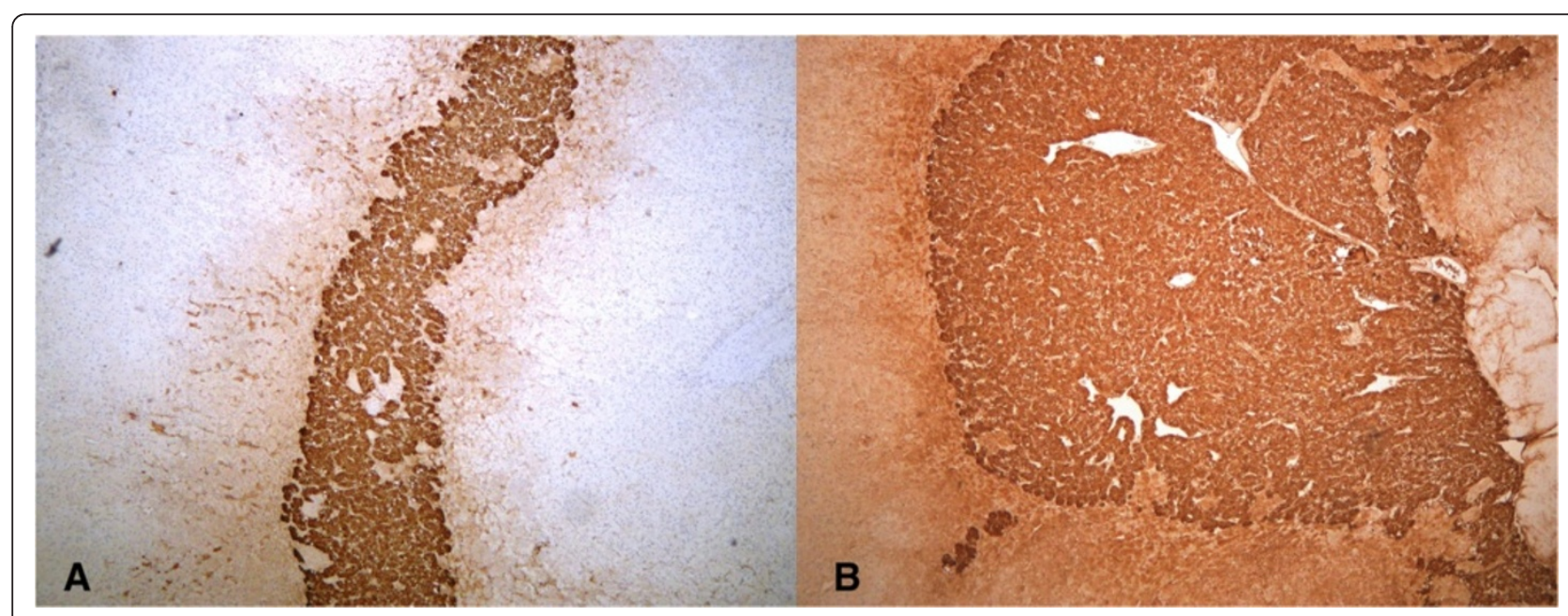

Figure 3 Adrenal medullary hyperplasia - AMH: chromogranin staining (40x magnification) in case one (A) and case two (B). 


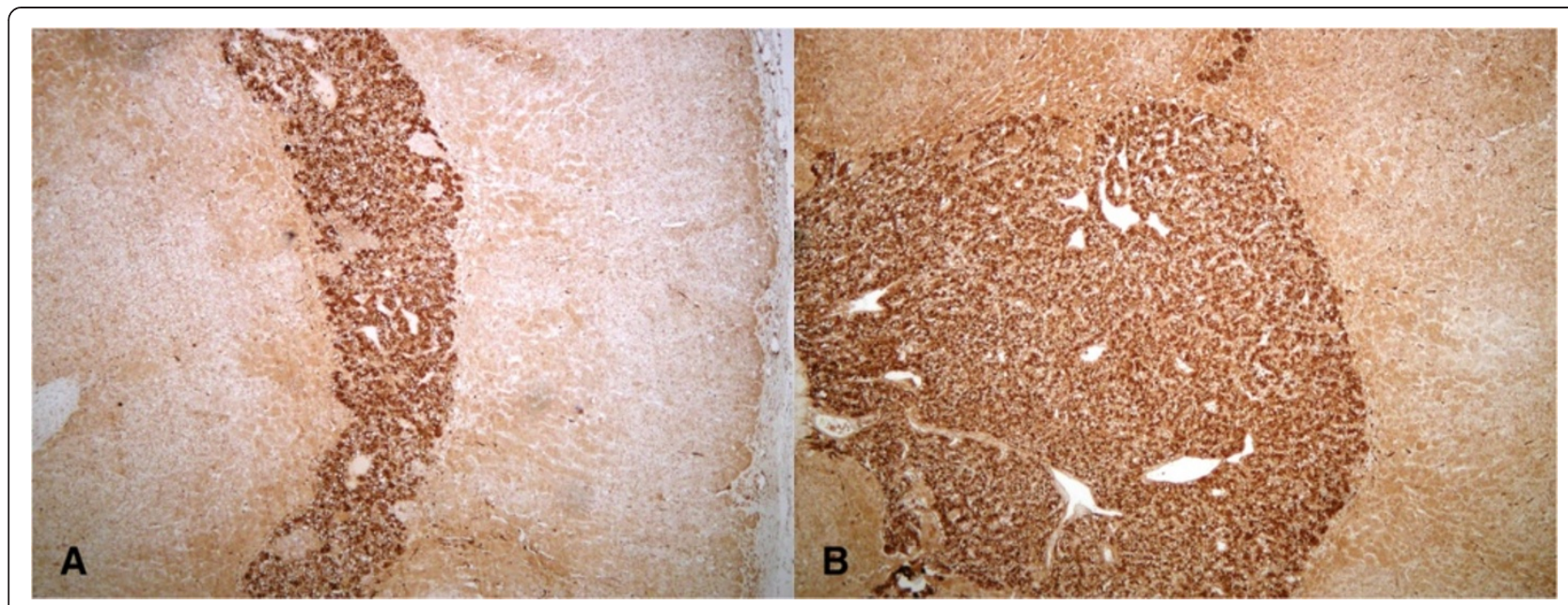

Figure 4 Adrenal medullary hyperplasia - AMH: S-100 staining (40x magnification) in case one (A) and case two (B).

adrenal tumor was found incidentally on a routine medical examination in 1997. There was no family history of any endocrine pathology and she did not present with any symptoms of palpitations, diaphoresis or flushing. Laboratory examinations revealed that the urinary vanilinmandelic acid, catecholamine and cortisol levels all were within normal limits (see Table 1).

The preoperative abdominal CT scan demonstrated a well-circumscribed, solid right adrenal mass measuring $88 \times 80 \times 90 \mathrm{~mm}$. Based on the above findings, the primary diagnosis was non-functional adrenal carcinoma. Subsequently, an open total left adrenalectomy was performed and no lymphadenopathy was seen. On gross

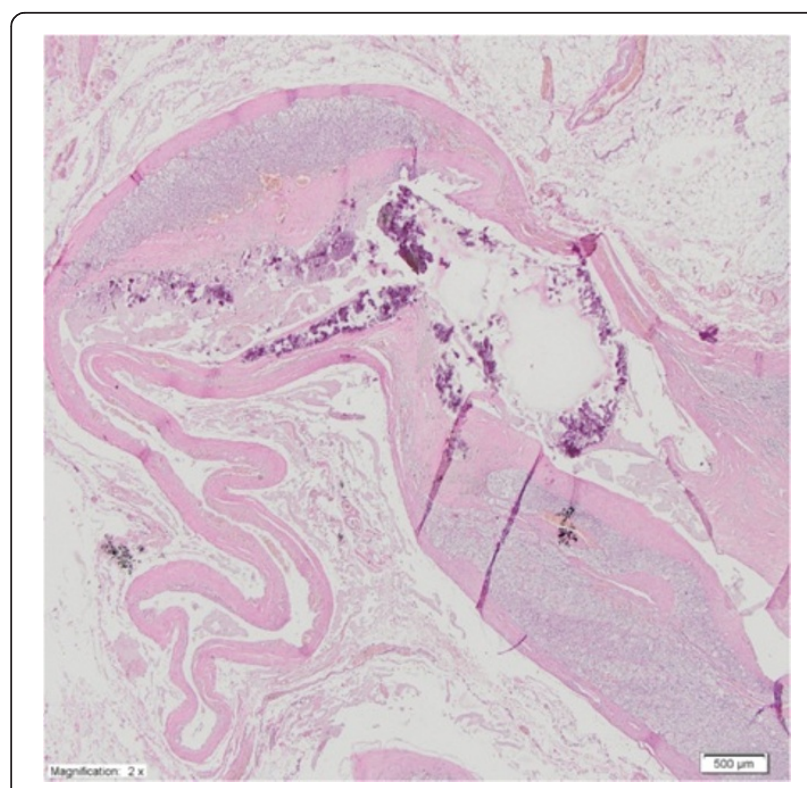

Figure 5 Case three - adrenal cyst. Calcific deposits are present in the fibrous wall. No lining epithelial or endothelial cells are evident in the cystic space ( $H$ \& E, $2 \times$ magnification). examination the tumor was a well-circumscribed solid mass. The histological appearance, together with the immunophenotype of this tumor, was consistent with the diagnosis of cystic lymphangioma-like AT of the adrenal gland (Figures 8 and 9).

\section{Discussion}

The adrenal glands are an extremely rare site of occurrence for an adrenal medullary hyperplasia, adenomatoid tumor, hydatid disease or primary adrenal angiosarcoma.

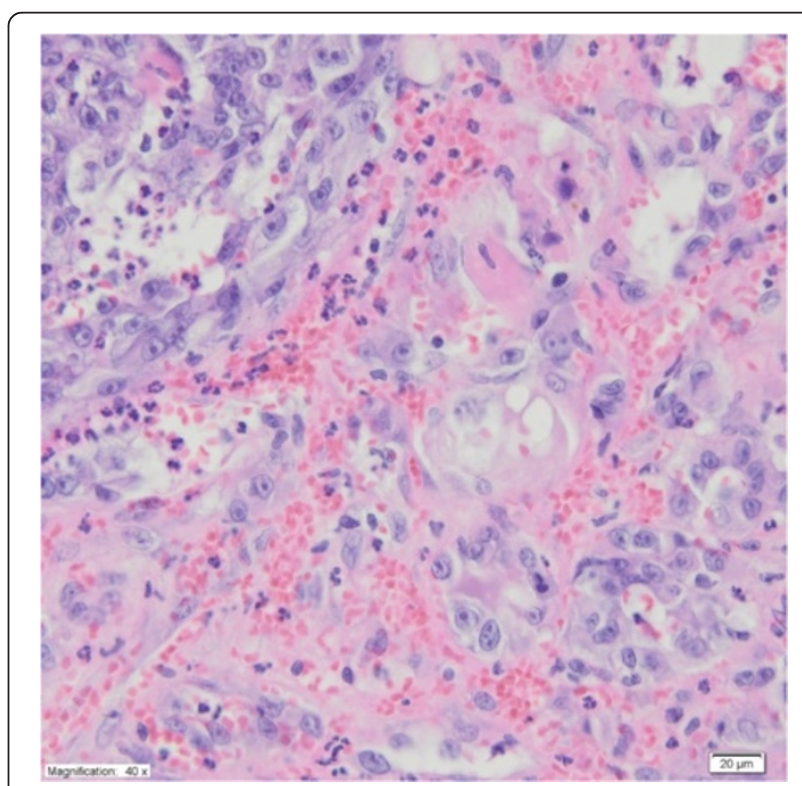

Figure 6 Case four: angiosarcoma of the adrenal gland is composed of anastomosing vascular channels lined by abnormal endothelial cells that are often pleomorphic, with large hyperchromatic nuclei and prominent nucleoli. Some of the cells contain cytoplasmic vacuoles and erythrocytes ( $H$ \& E, 40x magnification). 


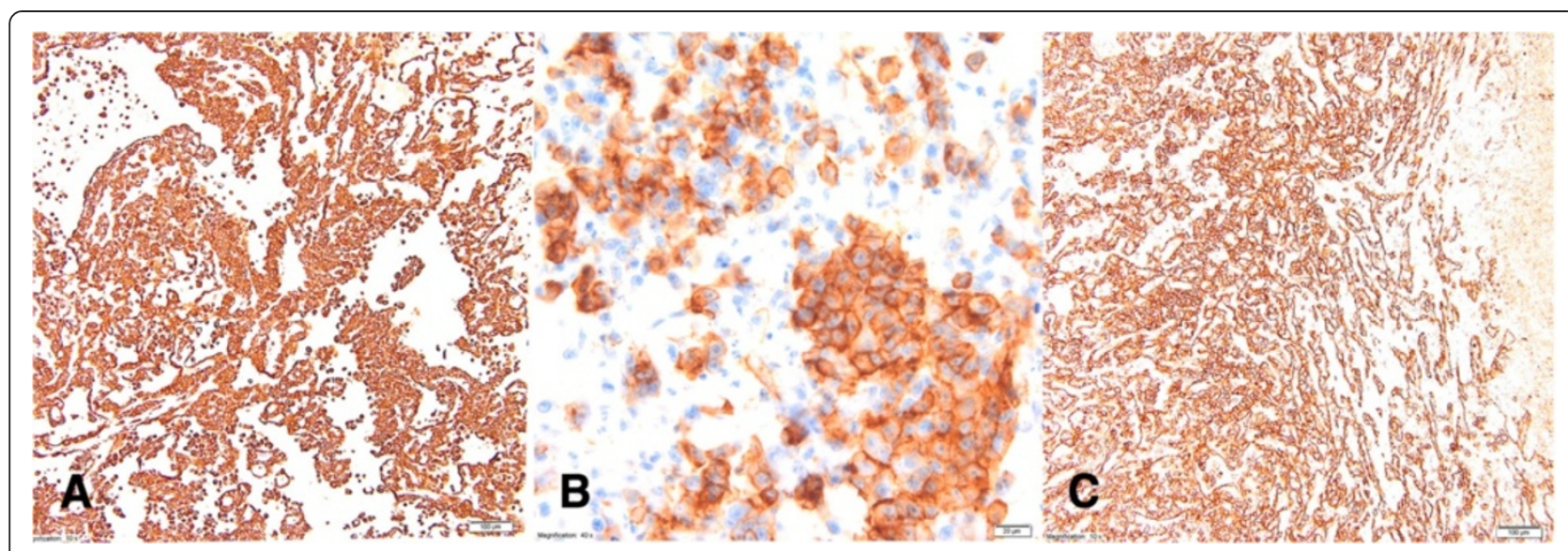

Figure 7 Case four: Immunohistochemical analysis of the angiosarcoma. CD31 staining (A) - 10x magnification; CD34 staining (B)- 40x magnification; vimentin staining (C) (10x magnification).

Unusual adrenal tumors are frequently misdiagnosed as primary or metastatic malignant enlargement.

$\mathrm{AMH}$ as a cause of hypertension and/or palpitations resembling pheochromocytoma is rare, and has been described in patients with multiple endocrine neoplasia (MEN). AMH, when present in patients with familial MEN type 2 (MEN2), usually occurs bilaterally. The occurrence of unilateral AMH not associated with MEN is extremely rare and has been documented only in several cases [3]. This hyperplasia is considered to precede pheochromocytoma in patients with MEN2 [4]. Carney defined a pheochromocytoma as a medullary nodule of $1 \mathrm{~cm}$ or larger [3-5]. The diagnosis of adrenal medullary hyperplasia is based on the following criteria: a history of episodic attacks of hypertension and/or tachycardia suggesting pheochromocytoma, combined with increased secretion of catecholamines; diffuse expansion of medulla in the adrenal gland with or without nodular formation; adrenal medulla composed of enlarged cells with or without pleomorphism; and an adrenal cortico-medullary ratio of less than 10:1 [3].

The patients described in this study had AMH without evidence of MEN2 or a family history of pheochromocytoma. A pathologic study showed diffuse adrenal medullary hyperplasia that decreased the cortico-medullary ratio. Because of the well-recognized metachronous nature of the adrenomedullary lesions, patients will maintain prolonged follow-up after successful unilateral adrenalectomy $[3,4,6]$. Normalization of catecholamines excretion and the lack of clinical sings (three (case one) and seven (case two) years following unilateral adrenalectomy) excluded bilateral AMH. Similar good results with conservative surgery in nonhereditary AMH have been reported by other authors [7].

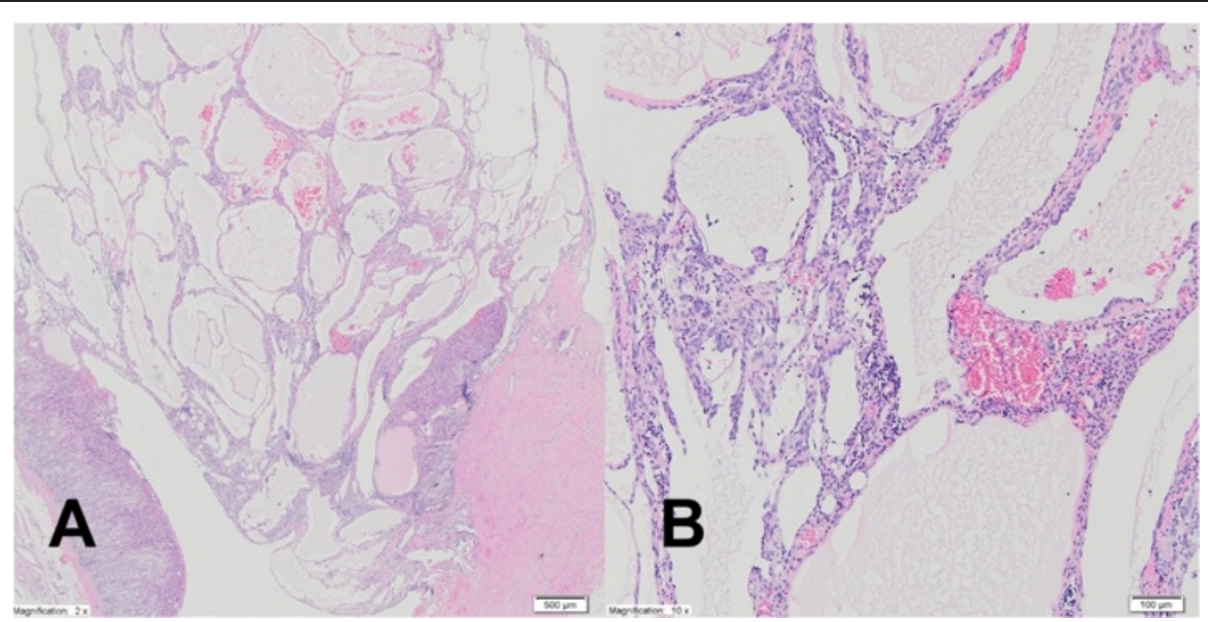

Figure 8 Case five: mesothelial cells forming dilated, irregular tubules with flattened lining cells which may initially suggest an endothelial orgin. There is a chronic inflammatory infiltrate in a fibrous stroma (A) $\mathrm{H} \& \mathrm{E} 2 \mathrm{x}$ magnification. At low power, tumor cells form fenestrated channels and anastomosing tubules of varying size, in the left corner there is residue normal adrenal gland parenchyme (B) $\mathrm{H}$ \& $\mathrm{E}$ 10x magnification. 


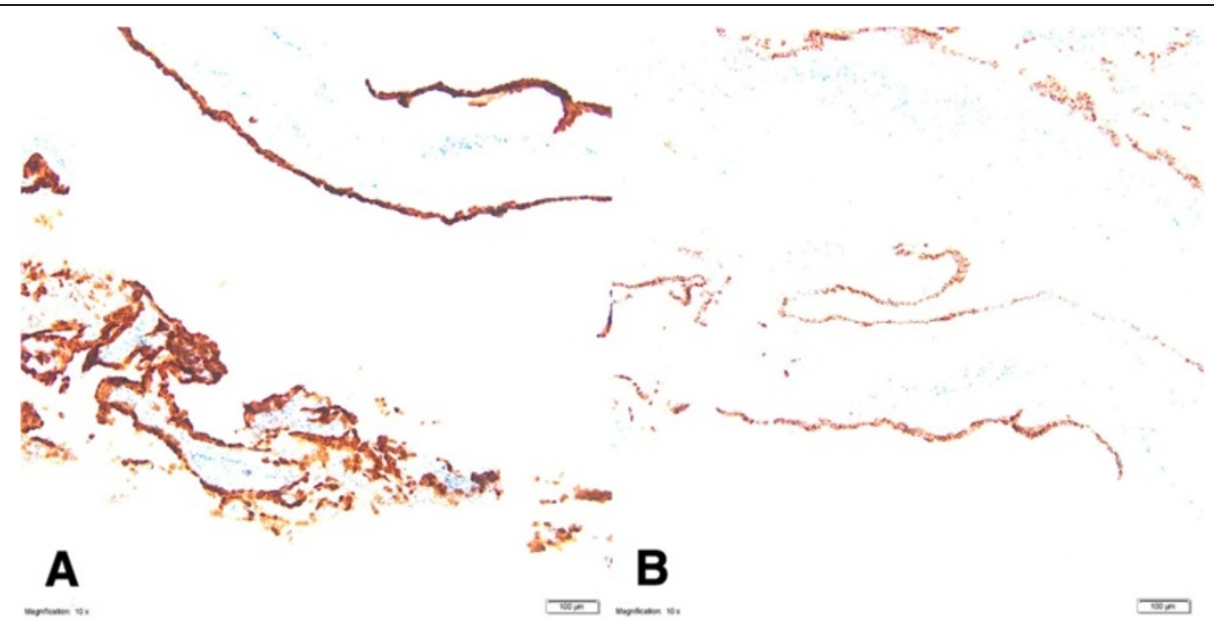

Figure 9 Case five: adenomatoid tumor cells show positive immunostaining for markers of mesothelial origin, such as calretinin (A) and CK 5/6(+) (B). 10× magnification.

Hydatid disease (Echinococcosis) is a parasitic infection caused by several species of the cestode Echinococcus. The most common form is Echinococcus granulosus; much less common is Echinococcus multilocularis. Hydatid cysts occur throughout the world but are endemic in the pastoral and farming regions of the Mediterranean, Eastern Europe, the Middle East, South America, Australia and South Africa $[8,9]$.

Hydatid cysts may be found in almost any part of the body, but most often they are found in the liver and lungs. A hydatid cyst of adrenal gland is very rare; this entity is found in only $7 \%$ of all adrenal cysts. Parasitic cysts involving the adrenals are usually secondary and are part of generalized Echinococcosis. Rarely is Echinococcus infection limited to the adrenal gland. Only a few cases of primary hydatid cyst of the adrenal gland have been reported [8]. Our patient (case three) had a primary hydatid cyst of the right adrenal gland.

Since most adrenal cysts are asymptomatic, they are usually incidental findings on imaging studies or discovered incidentally during surgery performed for other abdominal pathologies. The sensitivity of a CT scan in an abdominal hydatid cyst is $97 \%$. To identify a hydatid cyst, $\mathrm{CT}$ and/or magnetic resonance imaging can reveal a cystic lesion and the presence of daughter cysts $[8,9]$. On CT scans, concentric areas of separation and calcification indicate that a cyst is of parasitic origin. The most common presenting symptom is pain, accompanied by intra-cystic hemorrhage, rupture or infection. Anaphylactic shock may be caused by the rupture of hydatid cysts [9]. Our patient (case three) was completely asymptomatic and the adrenal tumor was detected incidentally. Hydatid disease of the adrenal gland with hormonal function has not been reported. Eosinophilia occurs in one fourth of cases and was present in our patient (case three). There are many sensitive and specific serological tests available, such as complement fixation, enzyme-linked immunosorbent assay, ARC 5 (activity regulated cytoskeleton) precipitation and specific hydatid IgE (Immunoglobulin E) tests. The sensitivity of serologic tests is $90 \%[8,9]$. We did not use specific tests because hydatid disease was not suspected.

The definitive treatment method for hydatid cysts of the adrenal gland is surgical excision [9]. We qualified our patient (case three) for surgery because of the malignancy risk (size greater than $4 \mathrm{~cm}$ ) [1,2], and the patient underwent laparoscopic total adrenalectomy. Most authors of previous reports performed adrenalectomy because of the destruction of the organs by a large cyst, but El Idrissi Dafali performed a simple cystectomy $[8,10]$. When peritoneal spillage is suspected, and when the patient has a coexistent peritoneal cyst, antihelmintic drugs are recommended [8].

PAA is an extremely rare aggressive neoplasm. The first example of PAA was described by Kareti in 1988 [11-14]. Patients usually present non-specific symptoms like abdominal pain. In most cases the lesion is over $6 \mathrm{~cm}$ [12]. On macroscopic examination, the tumor suggests pheochromocytoma or adrenal carcinoma. On histopathological examination, PAA displays epithelioid differentiation with large, rounded neoplastic cells with vesicular nuclei and prominent nucleoli. On immunohistochemical analysis, the angiosarcoma component expresses endothelial markers CD31, CD34 and, less extensively, von Willebrand factor (factor VIII) [12,13].

Angiosarcoma is a local invasive neoplasm. An open adrenalectomy and block resection approach would have been chosen for patients suspected of having PAA. This tumor is derived from vascular endothelial cells, therefore the traditional chemotherapy agents ifosfamide and 
epirubicin were used in combination with anti- angiogenic drugs bevacizumab or sorafenib. The chemotherapy plan for patient four was doxorubicin and ifosfamide but she refused the treatment. Bevacizumab is effective for angiosarcomas in $57 \%$ patients. Sorafenib provides a better progression-free survival, but the response rate is lower than standard cytotoxic agents. Radiation therapy may be not effective [12]. In the largest series of nine PAA tumors found in literature, thee patients survived, three died from the recurrence of the disease and three died of any other causes $[13,14]$. Our patient (case four) had recurrence of the disease and died after two years.

AT is a rare benign neoplasm of mesothelial origin which usually occurs in the genital tract of both sexes. Occasionally these tumors are found in other locations such as the heart, pancreas, skin, pleura, omentum, lymph nodes, retroperitoneum, intestinal mesentery and adrenal glands. So far in the English literature only 27 cases of adrenal AT have been described [15]. Most patients with the adrenal gland AT were men; only one tumor was reported in a woman. A possible explanation for this disproportion can be connected with the differences in embryological development of the gonads in both sexes, especially the different role of the mesonephric ducts in males and females $[15,16]$.

ATs are usually asymptomatic. In the available literature only one patient had symptoms which could be connected to the adrenal mass. In our patient (case five) the adrenal tumor was found incidentally.

The adrenal AT tumor can mimic all other entities occurring in this area such as adenomas, carcinomas, pheochromocytomas, myelolipomas, benign cystic lesions and metastases from distant locations. It may also be easily misdiagnosed as a vascular neoplasm (lymphangioma or angiosarcoma). The immunohistochemical profile was consistent with the one described in AT in usual locations (genital tracts) and was typical for a tumor of mesothelial origin: calretinin (+), CK(cytokeratin) 5/6 (+), CK 7(+), vimentin (+), D2-40 (+), CD31(-) and CD34 (-).

Numerous irregular cystic spaces lined with flattened cells may suggest a vascular neoplasm, especially lymphangioma. However, the cells are positive for CK and they lack reactivity to the usual vascular markers CD31, CD34, factor VIII, which exclude vascular tumors. It is important that AT may show reactivity to D2-40, a marker which is known to be positive in the endothelial cells of lymphatic vessels. In at least two cases reported in the literature, AT were primary misdiagnosed as lymphangioma cavernosum [16-18] similar to our case five.

Radiology has the important role in the detection of adrenal masses. CT is usually the primary imaging modality for the differentiation of adrenal masses. A large tumor diameter, unclear boundaries, infiltration of the neighboring structures, non-homogenous density and the presence of a thick, irregular peripheral zone becoming enhanced after contrast administration may suggest a malignant character of the lesion, however the specificity of those criteria does not exceed $75 \%$ [1,2]. Most centers recommend excision of a lesion sized $4 \mathrm{~cm}$ or more, as we advised in our department.

A medical history and physical examination may suggest possible cause. For example, paroxysmal hypertension may suggest a hormonally active mass, like in our AMH cases. Evaluation of hormonal excess should be done when imaging characteristics do not univocally suggest a necessity for surgery.

The clinician and surgeon must make the decision to operate jointly, trying to achieve the best calculus of what is known and predicted. Finally, histopathological examinations could be surprising.

\section{Conclusions}

In the differentiation of adrenal tumors, we should first take into consideration benign lesions, followed by malignancies, metastases and pheochromocytomas.

The suggestion of malignancy in CT scans was the reason for total adrenalectomy in three our cases.

Hormonal activity inclined us to laparoscopic adrenalectomy in two cases.

Finally, in all cases the final histopathological reports were surprising and unexpected.

\section{Consent}

Written informed consent was obtained from the patients for publication of this report and any accompanying images.

\section{Abbreviations}

AMH: Drenal medullary hyperplasia; ARC: Activity regulated cytoskeleton; AT: Adenomatoid tumor; CD: Cluster of differentiation; CK: Cytokeratin; $C T$ : Computer tomography; IgE: Immunoglobulin E; MEN: Multiple endocrine neoplasia; PAA: Primary adrenal angiosarcoma; USG: Ultrasonography.

\section{Competing interests}

The authors declare that they have no competing interests.

\section{Authors' contributions}

$A B$ is first author and reviewed the medical record and drafted the manuscript. RŚS researched the relevant literature. RP was involved in acquisition of data and preparing the figures. KS proofread and revised the manuscript. All authors approved the final manuscript.

\section{Author details}

${ }^{1}$ Department of Endocrinology and Internal Medicine, Medical University of Gdansk, Gdansk, Dębinki St 80-288, Poland. Department of Pathology, Medical University of Gdansk, Gdansk, Dębinki St 80-288, Poland.

Received: 31 May 2014 Accepted: 13 November 2014 Published: 8 December 2014

\section{References}

1. Babińska A, Siekierska-Hellmann M, Błaut K, Lewczuk A, Wiśniewski P, Gnacińska M, Obołończyk L, Swiątkowska-Stodulska R, Sworczak K: Hormonal activity in clinically silent adrenal incidentalomas. Arch Med Sci 2012, 8:97-103. 
2. Sworczak K, Babińska A, Stanek A, Lewczuk A, Siekierska-Hellmann M, Błaut K, Drobińska A, Basiński A, Łachiński A, Czaplińska-Kałas H, Grua Z: Clinical and histopathological evaluation of the adrenal incidentaloma. Neoplasma 2001, 48:221-226.

3. Qupty G, Ishay A, Peretz H, Dharan M, Kaufman N, Luboshitzky R: Pheochromocytoma due to unilateral adrenal medullary hyperplasia. Clin Endocrinol 1997, 47:613-617.

4. Cho KJ, Freier DT, McCormick TL, Nishiyama RH, Forrest ME, Kaufman A, Borlaza GS: Adrenal medullary disease in multiple endocrine neoplasia type II. Am J Roentgenol 1980, 134:23-29.

5. Carney JA, Sizemore GW, Tyce GM: Bilateral adrenal medullary hyperplasia in multiple endocrine neoplasia Type 2: the precursor bilateral pheochromocytoma. Mayo Clinics Proceedings 1975, 50:3-10.

6. DeLellis RD, Wolfe HJ, Gagel RF, Feldman ZT, Miller HH, Gang DL, Reichlin S: Adrenal medullary hyperplasia. Am J Pathol 1976, 83:177-190.

7. Jansson S, Khorram-Manesh A, Nilsson A, Kolby L, Tisell LE, Wangberg B, Ahlman H: Treatment of bilateral pheochromocytoma and adrenal medullary hyperplasia. Ann N Y Acad Sci 2006, 1073:429-435.

8. Akcay MN, Akcay G, Balik AA, Boyuk A: Hydatid cysts of the adrenal gland: review of nine patients. World J Surg 2004, 28:97-99

9. Ozarmagan S, Erbil Y, Barbaros U, Salmaslioglu A, Bozbora A: Primary hydatid disease in the adrenal gland: a case report. Braz I Infect Dis 2006, 10:362-363.

10. El Idrissi DA, Dahami Z, Zerouali NO: Hydatod cyst of arenal gland. Ann Urol 2002, 36:99-103.

11. Kareti LR, Katleni S, Siew S, Blauvelt A: Angiosarcoma of the adrenal gland. Arch Pathol Lab Med 1988, 112(11):1163-1165.

12. Lepoutre-Lussey C, Rousseau A, Ghuzlan AA, Amar L, Hignette C, Cioffi A, Zinzindohoue F, Leboullex S, Plouin PP: Primary adrenal angiosarcoma and functioning adrenocortical adenoma: an exceptional combined tumor. Eur J Endocrinol 2012, 166:131-135.

13. Wenig BM, Abbondanzo SL, Heffess CS: Epithelioid angiosarcoma of the adrenal glands: A clinicopatologic study of nine cases with a discussion of the implications of findings, epithelial - specific" markers. Am J Surg Pathol 1994, 18:62-73.

14. Kędzierski L, Hawrot-Kawecka A, Holecki M, Duława J: Angiosarcoma of the adrenal gland. Pol Arch Med Wew 2013, 123:502-503.

15. Garg K, Lee P, Ro JY, Qu Z, Troncoso P, Ayala AG: Adenomatoid tumor of the adrenal gland: clinicopathologic study of 3 cases. Ann Diag Pathol 2005, 9:11-15.

16. El-Daly H, Rao P, Palazzo F, Gudi M: A rare entity of an unusual site: adenomatoid tumor of the adrenal gland: a case report and review of the literature. Patholog Res Int 2010, 15:1-4.

17. Białas M, Szczepański W, Szpor J, Okoń K, Kostecka-Matyja M, Hubalewska-Dydejczyk A, Tomaszewska R: Adenomatoid tumor of the adrenal gland: a case report and literature review. Pol J Pathol 2010, 2:97-102.

18. Zhao M, Li C, Zheng J, Yan M, Sun K, Wang Z: Cystic lymphangioma - like adenomatoid tumor of the adrenal gland: report of rare cases and review of the literature. Int J Clin Exp Pathol 2013, 6:943-950.

doi:10.1186/1477-7819-12-377

Cite this article as: Babinska et al:: The collection of five interesting cases of adrenal tumors from one medical center. World Journal of Surgical Oncology 2014 12:377.

\section{Submit your next manuscript to BioMed Central and take full advantage of:}

- Convenient online submission

- Thorough peer review

- No space constraints or color figure charges

- Immediate publication on acceptance

- Inclusion in PubMed, CAS, Scopus and Google Scholar

- Research which is freely available for redistribution

Submit your manuscript at www.biomedcentral.com/submit
Biomed Central 